\title{
Age and Race as Factors in Craniofacial Growth and Development
}

\author{
James E. Harris, Gharles J. Kowalski, Frances A. LeVasseur, Carlos E. Nasjleti, and \\ Geoffrey F. WALKER
}

\author{
Dental Research Institute, School of Dentistry, The University of Michigan, and Veterans \\ Administration Hospital, Ann Arbor, Michigan 48105, USA
}

Large samples of adult American black and white males are being studied to determine the extent to which age and race are important fac. tors in craniof acial mophology and growth. It is shozon that a number of dentofacial dimensions continue to change throughout adulthood and that the amount and direction of these changes may be race-specific. Applications in orthodontics and prosthetic dentistry are indicated.

In carrying out its mission to improve the oral health of the people of the United States, the National Institute of Dental Research, under the direction of Dr. Seymour J. Kreshover, has provided substantial support for research in the areas of normal and aberrant growth, development and function of the dentofacial complex. One of the most exciting facets of this research is its inherent multidisciplinary nature. As noted by Dr. Kreshover in his Foreword to a conference on genetics, bone biology and the analysis of growth data in the context of human craniofacial growth, "In addition to the contributions of the clinical researcher, the skills of over 20 disciplines-ranging from genetics to physiology-have been tapped." In a similar vein, when sctring out the five-year plan of the NIDR for optimum development of the nation's dental research effort, ${ }^{2}$ he put special emphasis on the need "to attract scientists such as biometricians, developmental biologists, epidemiologists, psychologists and biochemists to studies relevant to this area of [dentofacial] malformation." It is hardly surprising then that the Dental Research Institute concept is so imbued with this spirit of cooperation, collaboration, and the interdisciplinary approach to the study of craniofacial growth and development. At The University of Michigan, we are especially fortunate to be a part of this endeavor and pleased to present this

Supported in part by the Medical Research Service of the Veterans Administration, Dental Research Institute Grant DE-02731.

Received for publication October 11, 1976.

Accepted for publication December 6, 1976. paper as a tribute to the man who made much of this research possible. We stand not as orthodontists, biostatisticians, anthropologists, and geneticists separately but, rather, as a team devoted to the solution of some of the problems cited as being of special importance by Dr. Kreshover," e.g., "Studies of the complex interaction of genetic and environmental influences on pre- and postnatal growth and development of the face to discover what initiates the malformation and how it develops." In this paper, then we extend our studies of the inheritance of dentofacial morphology $y^{3-6}$ and of the differences in dentofacial morphology within and between various ethnic/racial groups ${ }^{7-11}$ to a consideration of dentofacial changes throughout adulthood in American black and white males. ${ }^{12,13}$ Similar studies in the Netherlands ${ }^{14}$ and in the Scandinavian countries ${ }^{15-18}$ have demonstrated but few significant changes in later life, but the results of Garn et al. ${ }^{19}$ and Israel ${ }^{20-22}$ would tend to indicate that such changes do occur at least for certain dentofacial dimensions in some populations. Thus the purpose of the present paper is to test whether certain dentofacial measurements change with increasing age in the American black and white male population and, if so, to check whether the direction and amount of these changes are the same among blacks and whites.

\section{Materials and Methods}

The present investigation is based on cephalometric data obtained from the Veterans Administration Hospital in Ann Arbor, Michigan. Two groups of individuals are involved. The first group consists of a total of 244 black adult males ranging in age from 20 to 80 years; the second group consists of 1,039 white males in the same age range. Both groups were seen for care at the V.A. Hospital, but were selected to be otherwise representative of the American adult male population, i.e, only patients with "normal" medical histories were included in 


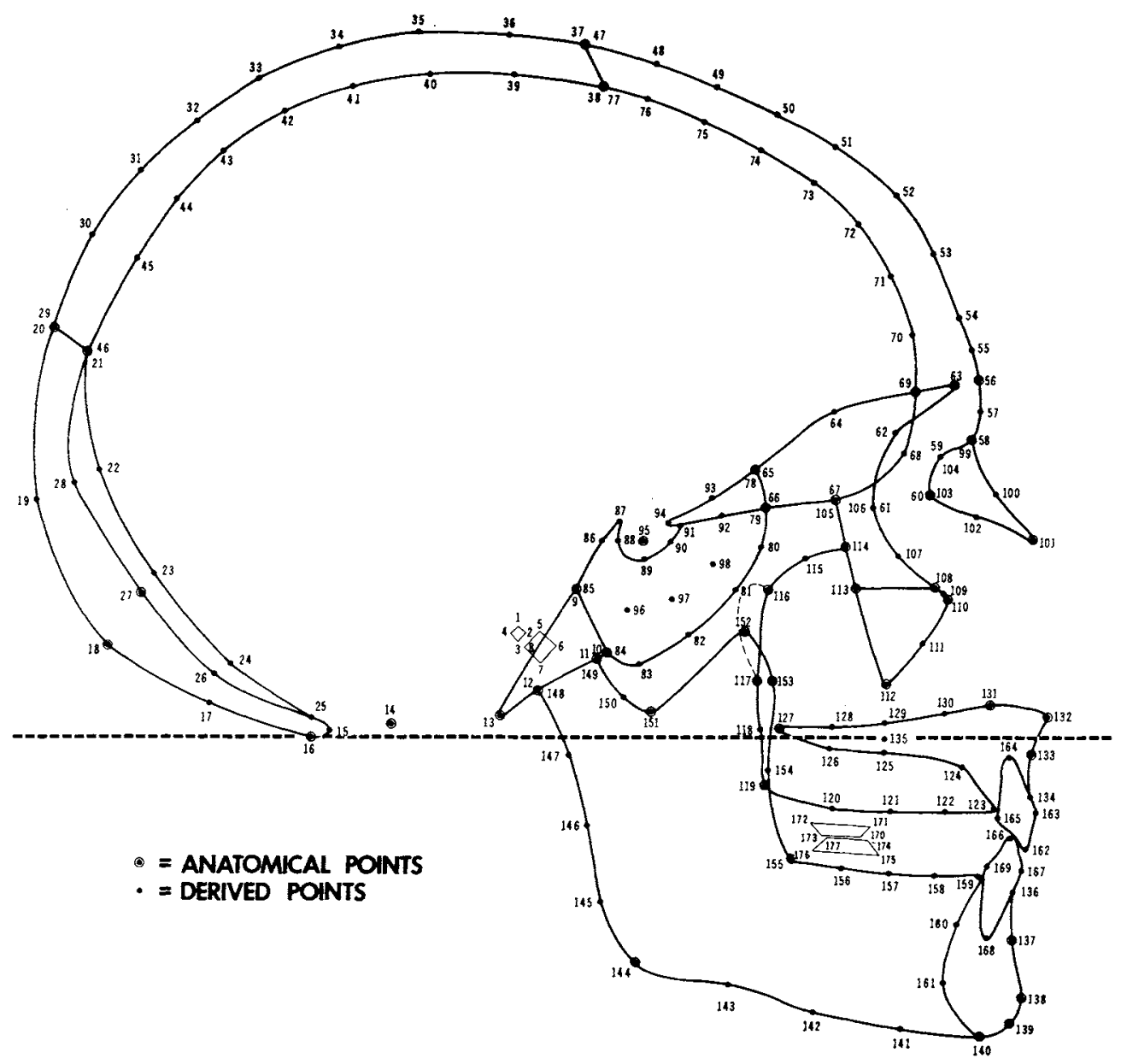

Fig 1.- The 177 coordinate points comprising our model of craniofacial morphology.

the study. Each were dentulous and had a sufficiently natural occlusion, with anterior and posterior centric stops, so that the measurements considered could be reliably determined in centric occlusion. The measurements reported here are defined in terms of the coordinate points shown in Figure 1 (cf Walker and Kowal$\mathrm{ski}^{23,24}$ ) and the age-specific sample sizes for the two groups are listed in the Table.

Here the age intervals are closed on the left and open on the right, i.e., the interval 20-30 includes all those who have attained 20 years of age but have not as yet celebrated their 30 th birthday. The measurements considered in this study are defined in terms of the coordinate points in Figure 1 in the following section where the age- and race-specific developmental curves are presented.
TABLE

Age-Spegific Sample Sizes for Adult Male American Black and White Populations

\begin{tabular}{crrr}
\hline Ages & Black & White & Totals \\
\hline $20-30$ & 80 & 407 & 487 \\
$30-40$ & 35 & 121 & 156 \\
$40-50$ & 66 & 246 & 312 \\
$50-60$ & 36 & 194 & 230 \\
$60-70$ & 16 & 39 & 55 \\
$70-80$ & 11 & 32 & 43 \\
Total & 244 & 1,039 & 1,283 \\
\hline
\end{tabular}

\section{Results}

Figures 2 through 11 show the agechanges for several dentofacial measurements for the black and white individuals. The de- 
finitions of the measurements considered are given on each figure in terms of the coordinate points shown in Figure 1. Thus, mandibular body length as shown in Figure 2 is defined as the distance between points \#144 and \#138, i.e., the length of the line connecting gonion and pogonion. Similarly, the width of the ramus (Fig 3) is defined as the distance between points \#146 and \#154. The mean values of these measurements are shown on the figures for each of the groups and for each age interval and the length of the vertical line is deternined by the mean value plus and minus one standard deviation.

\section{Discussion}

The purpose of Figures 2-11 is to demonstrate the importance of the factors of age and race in the description of dentofacial morphology. Many of the dimensions studied show definite changes with age and most also exhibit significant black/white differences. In Figures 2 and 3, no changes with age are apparent, but the black and white groups differ significantly at each age, the blacks having consistently longer mandibules and wider rami. Figures 4 and 5 are illustrations of the fact that certain measurements may vary over age in one race but remain relatively constant in the other. Both lower dental height and lower alveolar height decrease with age in the black sample while little change is evident among the whites. Blacks are considerably longer in these dimensions during the earlier age intervals, but the cxtent of this dimorphism decreases with increasing age. Three additional alveolar dimensions are considered in Figs 6-8 while no significant changes with age occur, these dimensions are considerably larger in blacks than they are in the white sample. In Figure 9, we have an example where both races cxhibit age changes but where the black/white differences hold up over most of the age range considered. Figures 10 and 11 illustrate the behavior of sevcral ratio measurements over time for the two races. The first is relatively constant within each of the racial groups over time, while the second tends to increase with increasing age. Significant black/white differences are apparent in each instance. Figure 11 shows that changes in shape-at least to the extent that ratios reflect shape-can occur throughout adulthood in American males.

These results are in accord with the results

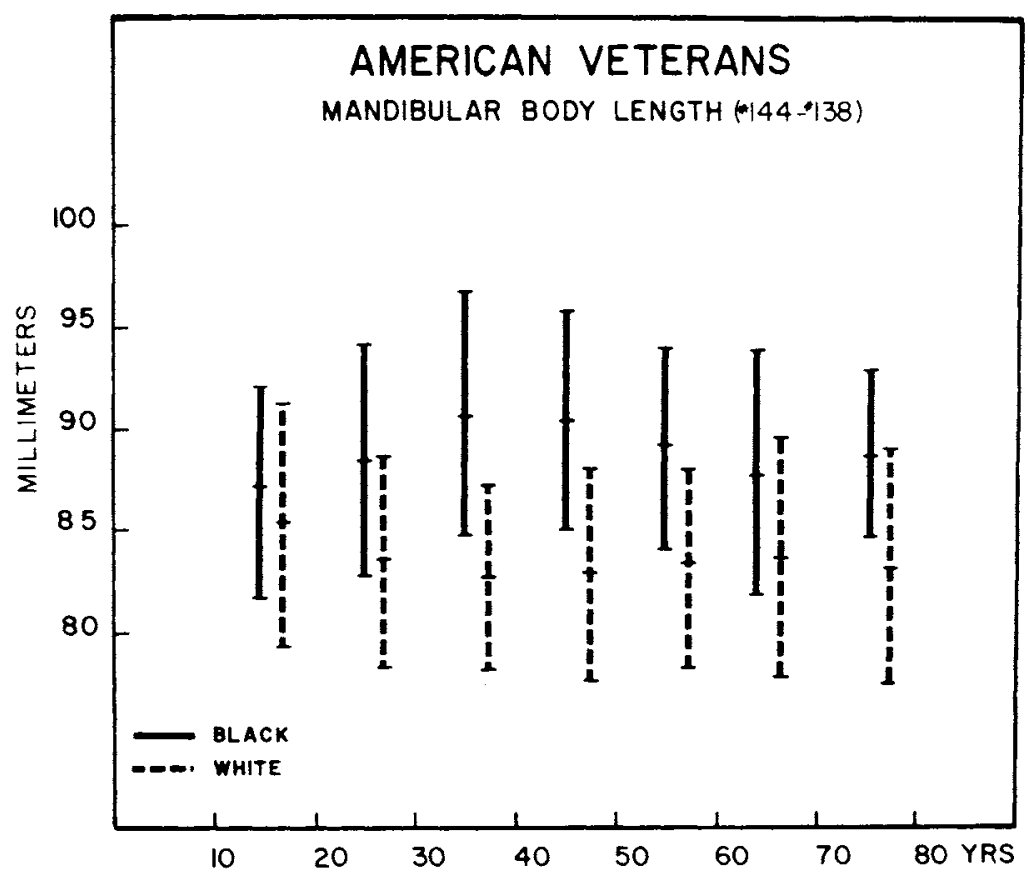

FIg 2.-Age- and race-specific developmental patterns for mandibular body length. 


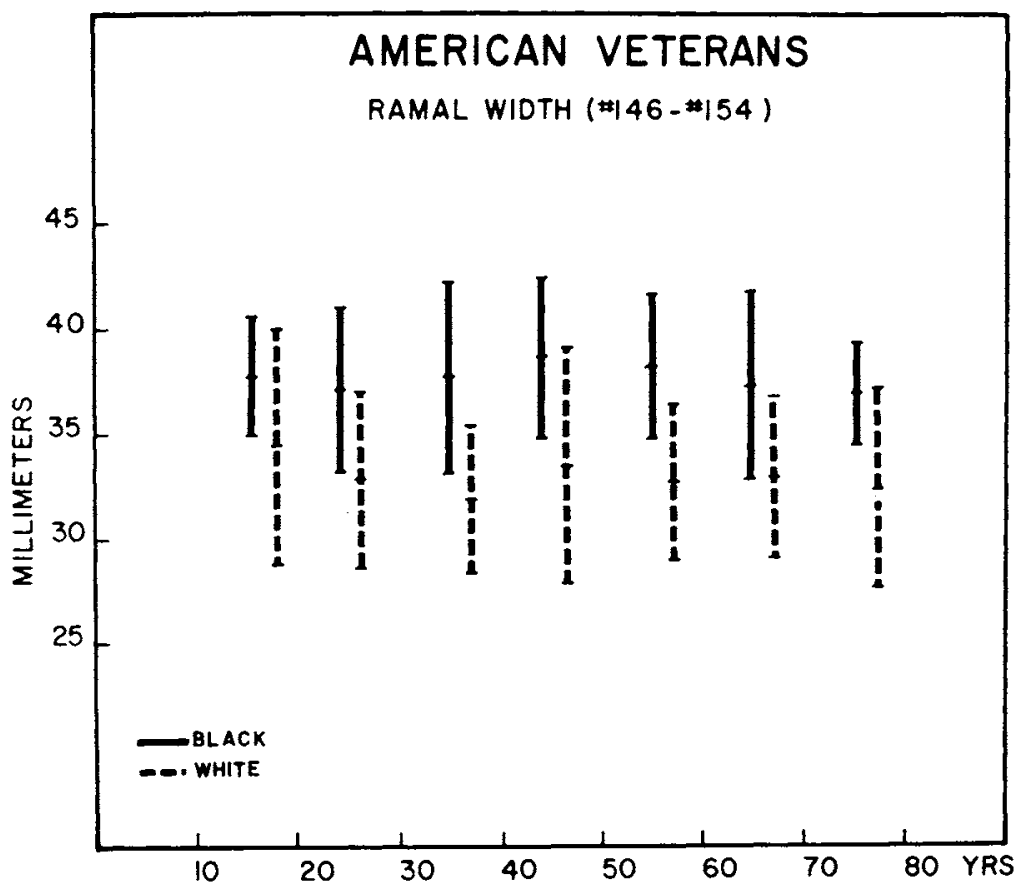

FIG 3.-Age- and race-specific developmental patterns for the width of the ramus.

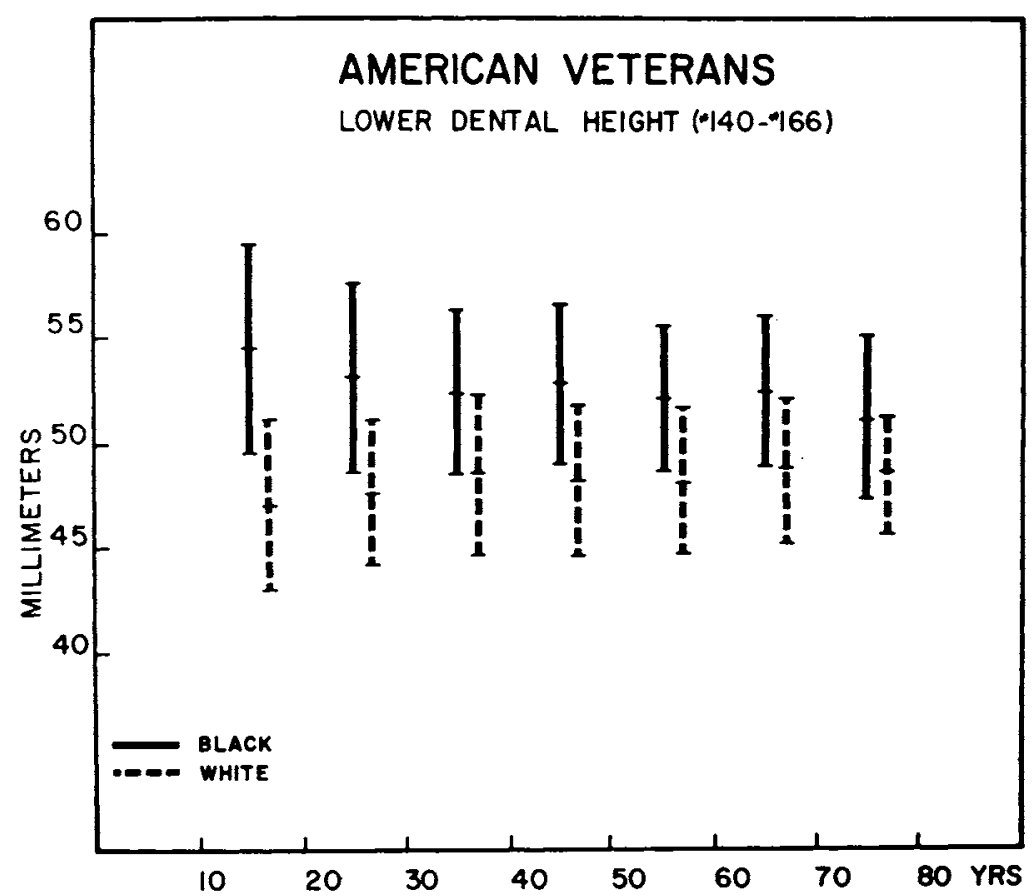
height.

Fig 4.- Age- and race-specific developmental patterns for lower dental 


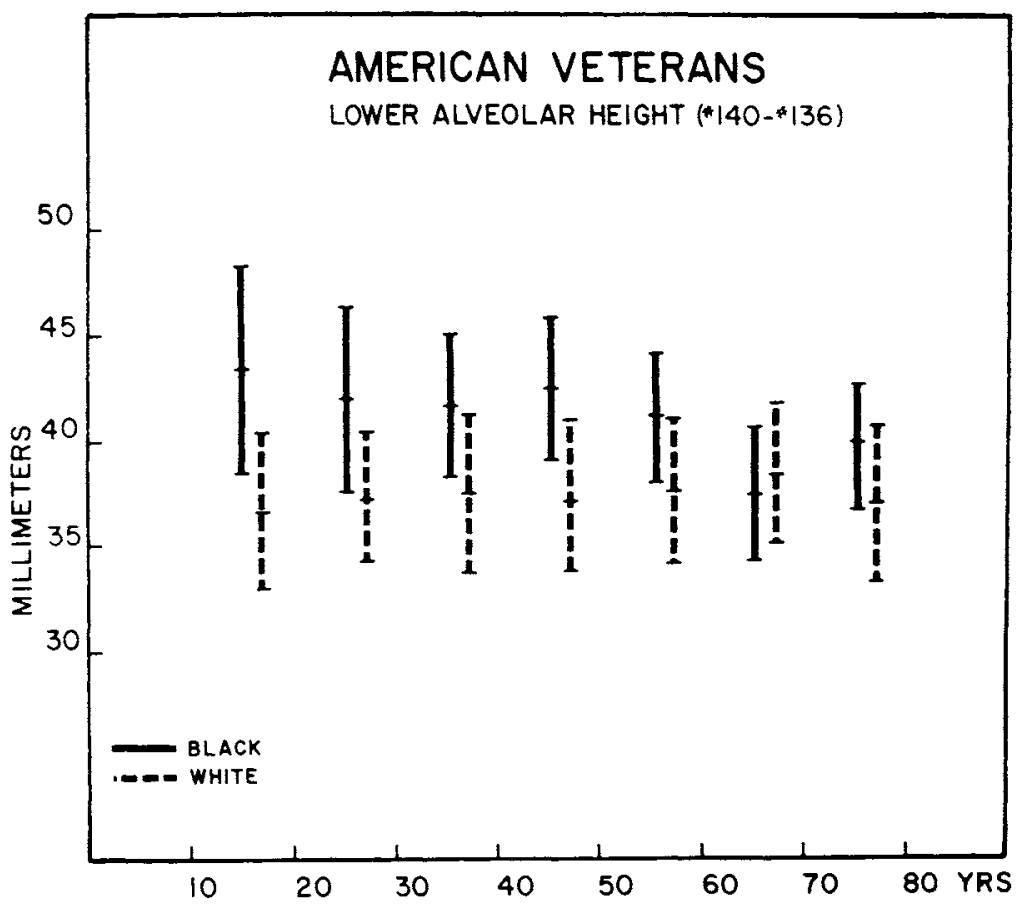

FIG 5.-Age- and race-specific developmental patterns for lower alveolar height.

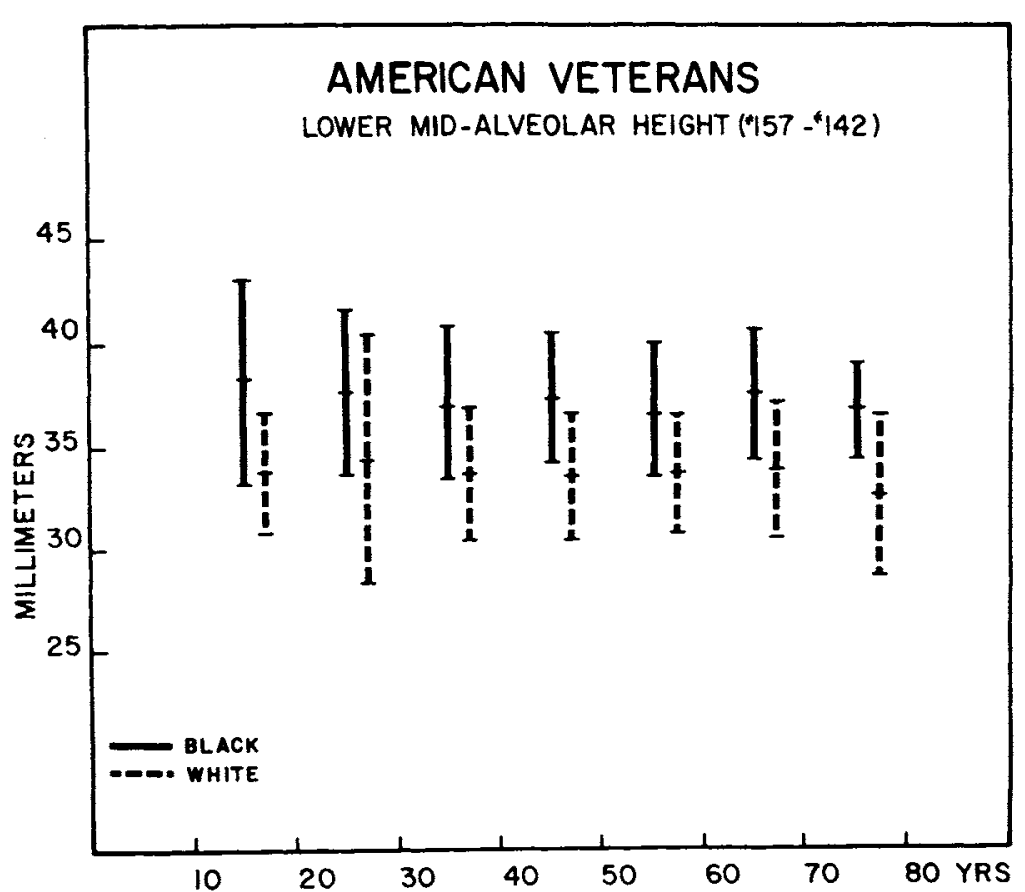

Frg 6.-Age- and race-specific developmental patterns for lower midalveolar height. 


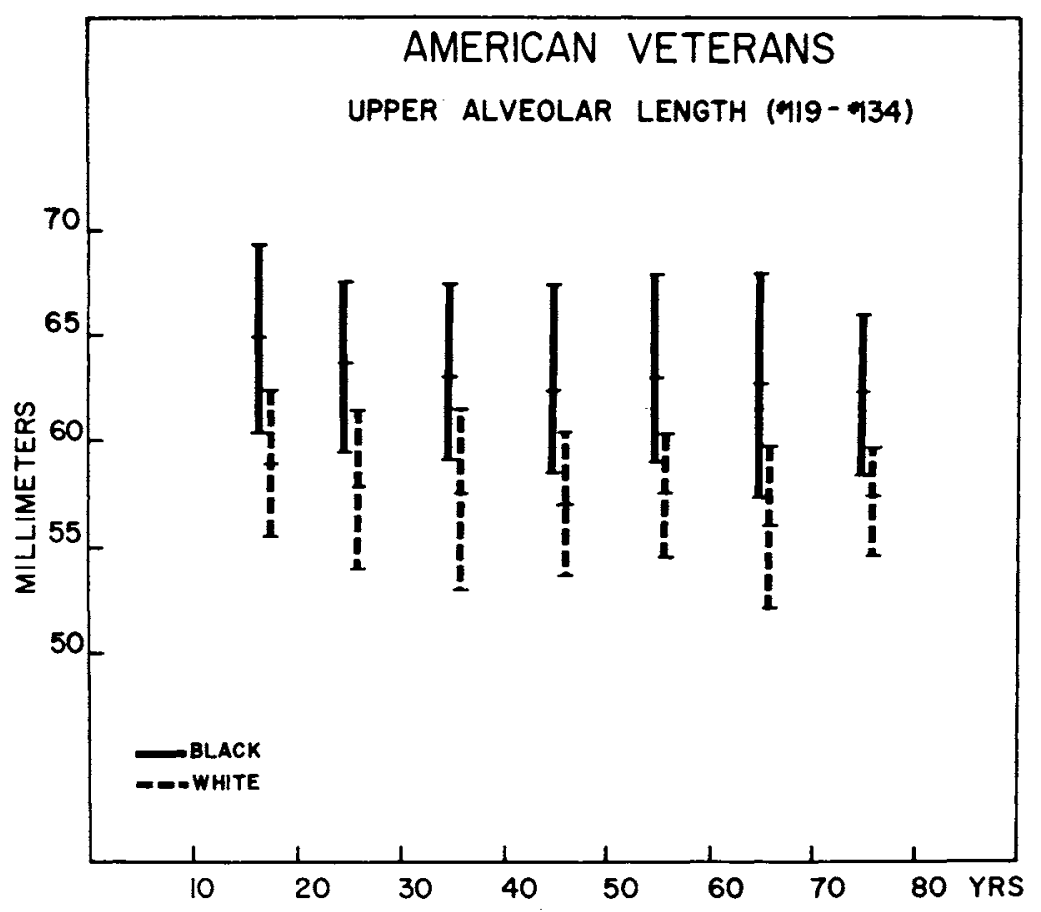
length.

FIG 7.-Age- and race-specific developmental patterns for upper alveolar

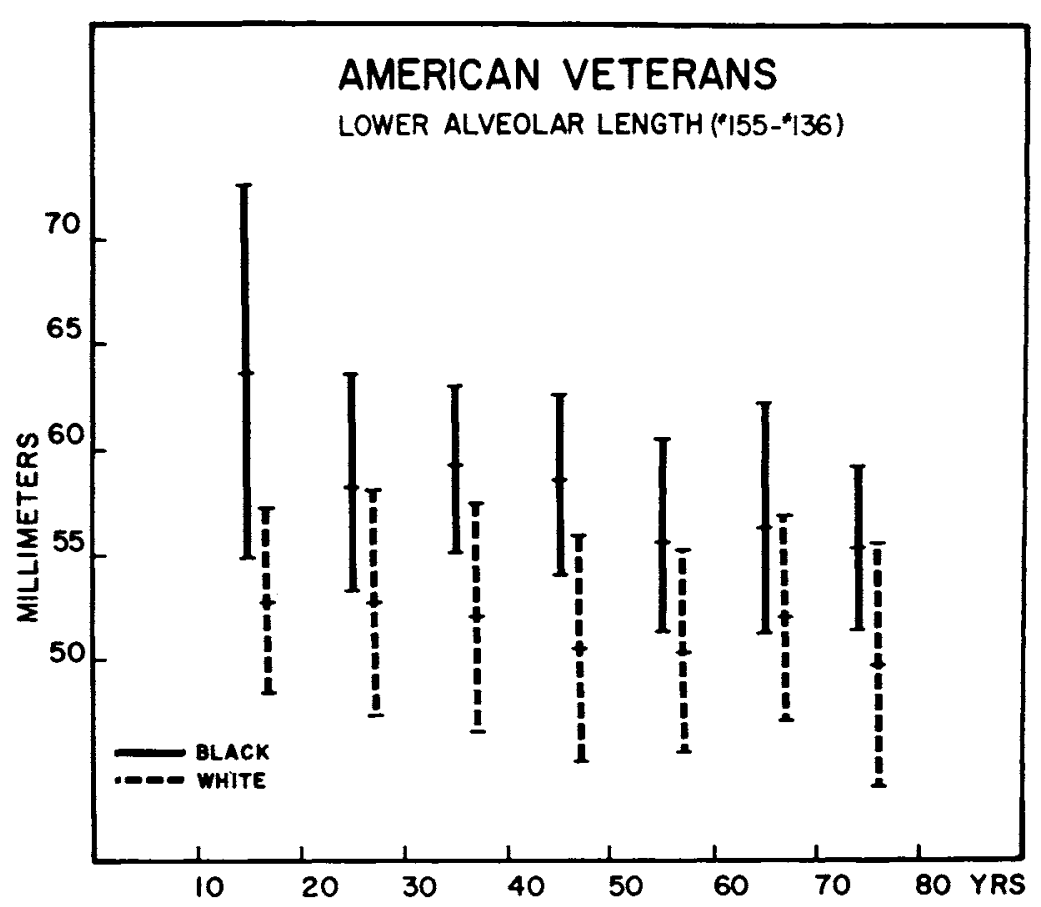
length.

Fig 8.-Age- and race-specific developmental patterns for lower alveolar 


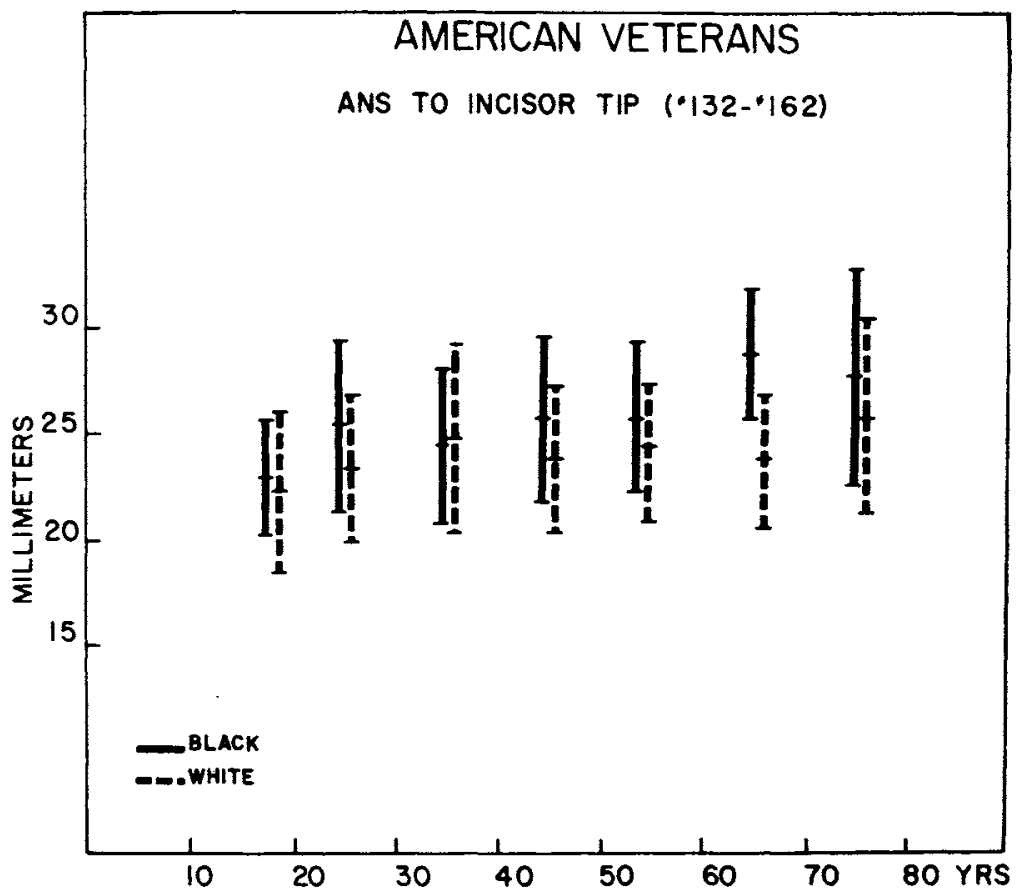

FIG 9.-Age- and race-specific developmental patterns for the distance between the anterior nasal spine and the tip of the lower incisor.

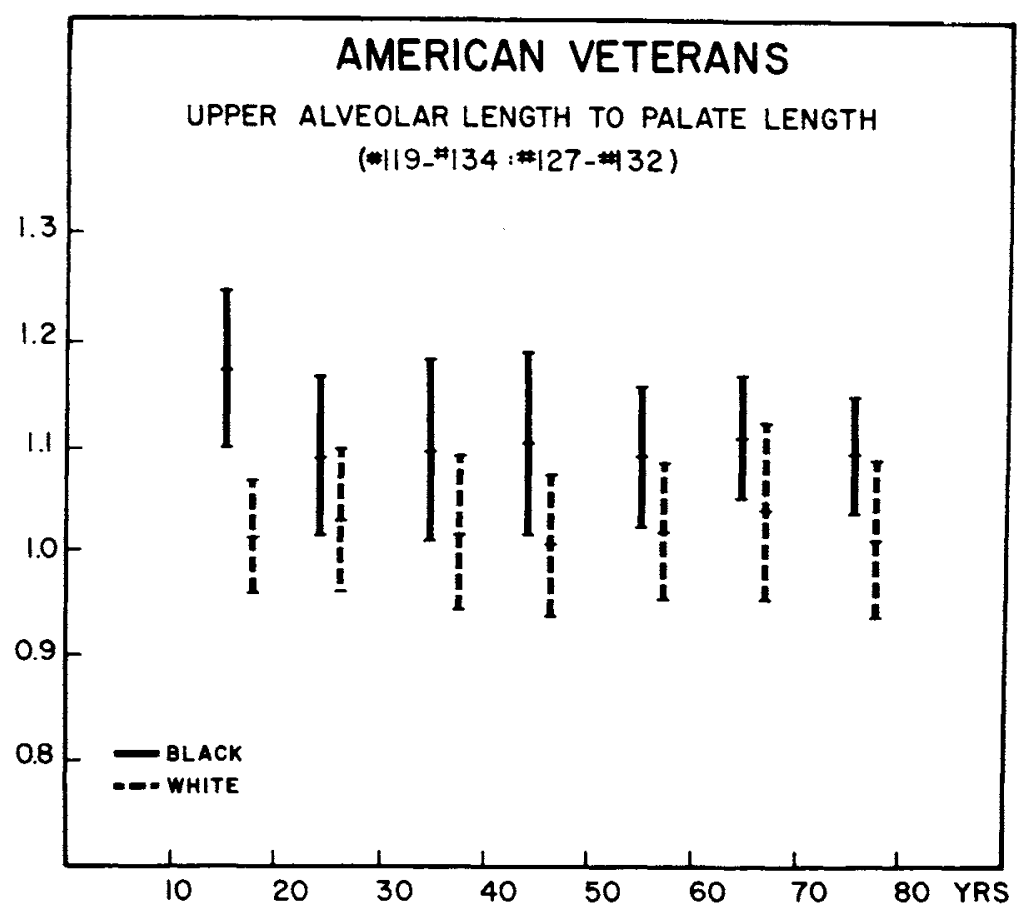

FIG 10.--Age- and race-specific developmental patterns for the ratio of upper alveolar length to the length of the palate. 


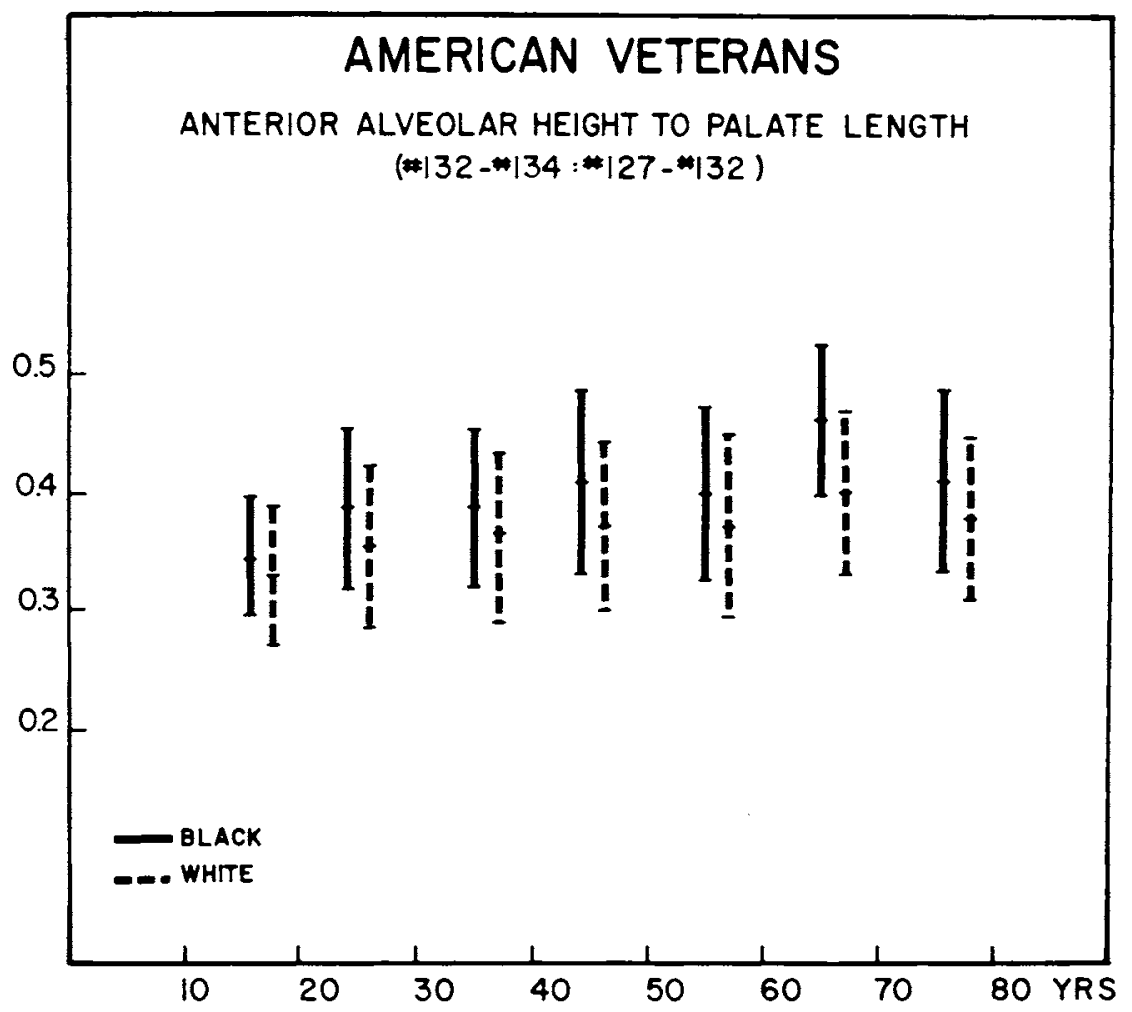

FIg 11.-Age- and race-specific developmental patterns for the ratio of anterior alveolar height to the length of the palate.

of several other studies which we carried out on data then available from the V.A. Hospital. Using a considerably smaller sample of white adult males (and the same 244 black individuals) we showed that a number of differences existed in the distributions of the Steiner variables in two populations. ${ }^{7}$ Since the Steiner battery includes a number of angular measurements, this provides some evidence that the two groups differ in shape ${ }^{25}$ as well as the differences in size which were pointed out in the context of the present study. These differences, while perhaps of some interest in-and-of-themselves, strongly suggest that different orthodontic norms, or "ideal values," may be necessary if we are to adequately treat both races, fully cognizant of the morphological differences that have been shown to exist. In addition, age has been identified as a potentially important factor in dentofacial development-both in terms of the size ${ }^{26}$ and shape ${ }^{25}$ of the craniofacial complex. While this finding is perhaps of limited importance in orthodontics, fruitful applications should abound in the field of prosthetic dentistry.

\section{Conclusions}

Age and race have been identified as important factors in the analysis of data on craniofacial morphology and development. In the American black and white populations, a number of craniofacial dimensions continue to change throughout adulthood and both size and shape measurements may differ in the two racial groups at any age.

\section{References}

1. Moyers, R.E., and Krogman, W.M. (eds): Cranio-facial Grozth in Man, New York: Pergamon Press, 1971, p. vii.

2. KRES hover, S.J.: Oral Disease: Targets for the $70^{\prime} s$, Washington: U.S. Department of Health, Education and Welfare, 1970.

3. Harris, J.E.; Kowalski, G.J.; and WatNICK, S.S.: Genetic Factors in the Shape of the Craniofacial Complex, Angle Orthodont 43:107-111, 1973.

4. Harris, J.E.; Kowalski, C.J. ; and WalkER, S.J.: Dentofacial Differences Between "Normal" Sibs of Class II and Class III Patients, Angle Orthodont 45:103-107, 1975. 
5. Harris, J.E.; Kowalski, C.J.; and WalkER, S.J.: Intrafamilial Dentofacial Associations for Class II, Division 1 Probands, $A m J$ Orthodont 67: 563-570, 1975.

6. Harris, J.E., and Kowalski, C.J.: All in the Family: Use of Familial Information in Orthodontics Diagnosis, Case Assessment and Treatment Planning, Am J Orthodont $69: 493-510,1976$.

7. Kowalskt, C.J.; Nas jleti, C.E.; and WALKer, G.F.: Differential Diagnosis of Adult Male Black and White Populations, Angle Orthodont 44:346-350, 1974.

8. Kowalski, G.J.; Nasjleti, G.E.; and WALKER, G.F.: Dentofacial Variations Within and Between Four Groups of Adult American Males, Angle Orthodont 45:146-151, 1975.

9. WALKER, S.J.; Harris, J.E.; and Kowalski, G.J.: SNA and SNB Angles in a Population of Nubian School Children, J Dent Res 54: 764-766, 1975.

10. Harris, J.E.; Kowalski, C.J.; and Wal.KER, S.J.: Distribution of the Mandibular Incisor/Mandibular Plane Angle in Nubian School Children. J. Dent Res 54:699, 1975.

11. Kowalski, C.J.; Harris, J.E.; and WalkER, S.J.: The Craniofacial Morphology of Nubian School Children, Angle Orthodont $45: 180-184,1975$.

12. Nas Jletr, G.E., and Kowalski, G.J.: Stability of Upper Face Height-Total Face Height Ratio with Increasing Age, $J$ Dent Res 54:1241, 1975.

13. Kowalski, G.J., and NaS Jletr, C.E.: Upper Face Height-Total Face Height Ratio in Adult American Black Males, J Dent Res 55:913, 1976 .

14. Boersma, H.: Alteration of Skull Dimensions in Aged Persons, J Dent Res 53:678682, 1974.

15. TallgRen, A.: Neurocranial Morphology and Ageing-A Longitudinal Roentgen Cephalometric Study of Adult Finnish
Women, Am J Phys Anthrop 41:285-293, 1974.

16. Taligren, A.: Changes in Adult Face Height Due to Ageing, Wear and Loss of Teeth and Prosthetic Treatment. A Roentgen Cephalometric Study Mainly on Finnish Women, Acta Odont Scand 15:suppl. 24, 1957.

17. Tallgren, A.: The Effect of Denture Wearing on Facial Morphology, A 7-Year Longitudinal Study, Acta Odont Scand 25:563$592,1967$.

18. Tallgren, A.: The Continuing Reduction of the Residual Alveolar Ridges in Complete Denture Wearers: A Mixed-Longitudinal Study Govering 25 Years, J Prosth Dent, 27: $120-132,1972$.

19. Garn, S.M.; Rohmann, C.G.; Wagner, B.; and Ascolr, W.: Continuing Bone Growth Throughout Life: A General Phenomenon, Am J Phys Anthrop 26:313--317, 1967.

20. Israei, H.: Continuing Growth in the Human Cranial Skeleton, Arch Oral Biol 13: 133-138, 1968.

21. Israel, H.: Recent Knowledge Concerning Craniofacial Aging, Angle Orthodont 43: 176-184, 1973.

22. Israel, H.: Age Factor and the Pattern of Change in Graniofacial Structures, $A m J$ Phys Anthrop 39:111-128, 1973.

23. WALker, G.F., and Kowalski, C.J.: A Two-Dimensional Coordinate Model for the Quantification, Description, Analysis, Prediction and Simulation of Craniofacial Growth, Growth 35:191-211, 1971.

24. Wal Ker, G.F., and Kowalski, G.J.: Gomputer Morphometrics in Craniofacial Biology, Comp Biol Med 2:235-249, 1972.

25. Walker, G.F., and Kowalski, C.J.: Use of Angular Measurements in Cephalometric Analyses, J Dent Res 51:1015-1021, 1972.

26. WALKER, G.F., and Kowalski, G.J.: On the Growth of the Mandible, Am J Phys Anthrop $36: 111-117,1972$. 